\title{
Relato de Experiência: I Simpósio de Humanidades da Escola Estadual Regina Pacis
}

\author{
Experience Report: 1st Humanity Symposium at Regina Pacis
}

\author{
Cristina de Oliveira Figueiredo \\ Mestra na Universidade Federal de Ouro Preto, Ouro Preto, MG, Brasil. \\ cristinadeoliveira00@hotmail.com - https://orcid.org/0000-0002-7435-3701

\section{Yasmin do Rego Lucas} \\ Graduanda na Universidade Federal de Ouro Preto, Ouro Preto, MG, Brasil. \\ yasminlucas71@gmail.com - https://orcid.org/0000-0003-3420-950X
}

RESUMO: O presente artigo é um relato de experiência sobre o primeiro I Simpósio de Humanidades da Escola Regina Pacis, em Raul Soares/Minas Gerais. O objetivo do evento era levar uma educação acentuadamente crítica e interdisciplinar aos seus estudantes, para além dos padrões tradicionais da sala de aula. A proposta era de tornar os jovens estudantes protagonistas e organizadores do simpósio. $E$ ainda, nós graduandas em filosofia, fomos convidas a ministrar duas palestras sobre "O que faz o ser humano ser tão especial?". Nesse relato pretendemos abordar a experiência de participar de um simpósio em uma rede estadual com estudantes do ensino médio, enxergando, assim, uma possibilidade de ensino/aprendizagem bastante pertinente. Além do mais, percebemos que é frutífera a aproximação da filosofia da educação de Mathew Lipman para uma leitura do simpósio.

Palavras-chave: Ensino de Filosofia; Sala de Aula; Escola; Simpósio; Humanidades.

ABSTRACT: This article is an experience report about the first Humanities Symposium at the Regina Paci's School, in Raul Soares/Minas Gerais. The main purpose of the event was to bring a sharply critical and interdisciplinary education to its students, beyond the traditional classroom standards. The proposal was to make young students protagonists and planners of the symposium. And yet, we graduate in philosophy, were invited to give two lectures on "What makes human beings so special?". In this report we intend to address the experience of attending a symposium in a public school with high school students, seeing in this event a possibility of teaching/learning quite pertinent. Furthermore, we realize that the approach of Mathew Lipman's philosophy of education is fruitful to a reading of the symposium.

Keywords: Teaching of Philosophy; Classroom; School; Symposium; Humanities.

\section{Introdução}

No mês de outubro do ano de 2019, os professores Walter Vieira Júnior (filosofia) e Márcio Pereira (sociologia) fizeram do seu sonho uma realidade, isto é, realizaram o $1^{\circ}$ Simpósio de Humanidades na Escola Estadual Regina Pacis, em Raul Soares/Minas Gerais, cujo tema era: "O que faz o ser humano especial?". O intuito do simpósio era 
promover a seus estudantes uma experiência de ensino que instigasse o pensamento crítico e a formação humanitária. Para a realização do evento, conseguiram movimentar todo o corpo estudantil - composto por estudantes do ensino médio - e administrativo da escola, e, também, houve uma intensa contribuição da comunidade. Além de tudo, nós, autoras deste presente artigo, graduandas em licenciatura em filosofia pela Universidade Federal de Ouro Preto, fomos convidadas a participar de duas mesas redondas e demais atividades realizadas pelos estudantes.

À vista disso, o presente artigo tem como objetivo relatar a experiência do $1^{\circ}$ Simpósio de Humanidades na Escola Estadual Regina Pacis, atentando para as nossas considerações sobre o ensino filosófico. Para tanto, no primeiro momento iremos escrever sobre o relato de experiência, ou seja, faremos uma descrição de como o evento ocorreu e o papel dado aos estudantes nesse simpósio; e, posteriormente, discutiremos a metodologia que será apoiada na filosofia de ensino do filósofo estadunidense Matthew Lipman. Contudo, faz-se necessário destacar que tal metodologia é uma leitura de nós, autoras, sobre o evento. Percebemos que é frutífera a aproximação do pensamento de Lipman com o simpósio ocorrido na Escola Estadual Regina Pacis. Isto significa que, o evento não fora calcado na filosofia do ensino do filósofo em questão, mas sim, trata-se de uma percepção das autoras.

Por outro lado, ao pensarmos sobre o nosso papel como graduandas em licenciatura em filosofia destacamos que, para uma universidade que pretende formar seus estudantes baseados em uma educação científica, política e profissional, três eixos devem ser explorados, são eles: o ensino, a pesquisa e a extensão. É fulcral a participação de graduandos em espaços como este, pois ao levar as experiências acadêmicas de pesquisa em forma de ensino e extensão para os estudantes do ensino médio, inicia-se, desse modo, uma expansão da vida intelectual, tanto para o graduando quanto para os estudantes da escola em questão. Nesse sentido, o graduando tem a oportunidade de colocar em prática os métodos de aprendizagem e ensino; enquanto o estudante do ensino médio tem a possibilidade de aproximar-se do meio acadêmico e, dessa forma, contribuir para o seu florescimento intelectual. 
Sendo assim, debruçaremos sobre o impacto desse simpósio no ensino de filosofia no ensino médio. É necessário debatermos e explorarmos novos métodos de ensino que promovam um espaço comunitário de aprendizagem, que fujam do âmbito tradicional vertical e hierárquico professor/estudante. Além disso, como futuras professoras, experiências como estas se tornam essenciais tanto para a vivência da licenciatura quanto para a aproximação da universidade com as escolas. No tópico subsequente, podemos ler sobre o relato do simpósio.

\section{Relato do Simpósio}

Contou-se com o apoio de diversas pessoas para a realização do 1 Simpósio de Humanidades da Escola Estadual Regina Pacis. Na escola, além da contribuição dos estudantes do ensino médio, tanto o corpo administrativo quanto os professores de outras disciplinas estavam presentes; ainda mais, os moradores da cidade de Raul Soares/MG apostaram no evento e doaram desde pastas, canetas e blocos de folhas a crachás e lanches para a sua realização; e, por fim, contou com a participação de uma ex-aluna da escola e, nós, graduandas do curso de licenciatura em filosofia da Universidade Federal de Ouro Preto.

A proposta geral do simpósio era discutir a respeito do que faz o ser humano especial nas seguintes grandes áreas: filosofia, sociologia, geografia e história, ou seja, o simpósio foi conduzido sob a perspectiva da interdisciplinaridade. Considerando o cenário de violência e desumanização, o objetivo era discutir sobre humanidade, e, dessa forma, trazer à tona os aspectos de responsabilidade social, ambiental e humana para si e para com o outro. Para tanto, foram realizadas duas mesas redondas principais e oficinas preparadas e ministradas pelos próprios estudantes, sob orientação dos professores Walter Vieira Júnior (filosofia) e Márcio Pereira (sociologia).

A organização do evento foi disposta da seguinte forma; a saber: os estudantes dos primeiros anos foram ouvintes do simpósio; os estudantes dos segundos anos foram comunicadores das oficinas; e os dos terceiros anos foram responsáveis pela parte operacional. Assim, as oficinas foram divididas em mesas simultâneas das quatro grandes 
áreas do conhecimento, isto é, cada estudante preparou o conteúdo proposto e devidamente corrigido pelos professores e se encarregou de apresentar para a escola. Dessa forma, a proposta que recebemos era de participar diretamente das duas mesas principais, que aconteceram ao longo do dia, e, posteriormente, participar como ouvintes e mediadoras das oficinas de filosofia. Em continuação com a descrição do relato do simpósio, o próximo tópico tratar-se-á sobre a exposição das principais mesas do evento e, posteriormente, a apresentação que os estudantes da escola fizeram em suas oficinas.

\section{Mesas principais}

O tema do $1^{\circ}$ Simpósio de Humanidades na Escola Estadual Regina Pacis era: "O que faz o ser humano especial?". Fora pedido para nós, autoras desse artigo, que apresentássemos duas palestras sobre tal querela para os estudantes nas principais mesas do evento. Para tanto, escrevemos dois breves ensaios, uma vez que seriam duas mesas principais, uma no turno da manhã e a outra no período da tarde.

Na primeira mesa, escrevemos um ensaio cujo título era Dos Rostos que Olham para Outros Rostos, o objetivo da nossa fala era provocar os estudantes com a ideia do cuidado de si e do outro, para que desse modo, a noção de responsabilidade pela alteridade fosse evocada. Trouxemos a lume o aforismo socrático "conhece-te a ti mesmo", para que assim, tal noção produzisse reflexões nos estudantes sobre as suas ações e os seus pensamentos. A maestria socrática desvela-se na consciência de si mesmo, em consonância com Pierre Hadot:

\footnotetext{
O diálogo socrático aparece, assim, portanto, como um exercício espiritual praticado em comum que convida ao exercício espiritual interior, isto é, ao exame da consciência, à atenção a si, em síntese, ao famoso 'conhece-te a ti mesmo (HADOT, 2014, p.38).
}

Conduzimos a discussão de tal modo a mostrar como o aforismo socrático pode desaguar na noção de alteridade, pois uma das possibilidades de acontecimentos provenientes desse autoconhecimento é a percepção pela vida do outro que salta aos seus olhos. A partir da Ética da Alteridade elaborada pelo ethos da cultura judaica do 
filósofo Emmanuel Lévinas, descortinamos a possibilidade ética da qual a vida é existenciada, mais precisamente, sobre a ótica do conceito de rosto. O rosto, como entendido na filosofia de Lévinas, não assume um caráter plástico (boca, nariz, olhos, etc.), evoca, porém, um discurso que propõe a alteridade, ou seja, "em sua nudez, o rosto do outro se apresenta como uma interpelação a mim dirigida, abrindo-me para a exterioridade" (ROSA, 2012, p.22).

Ainda que se trate de um assunto denso em termos filosóficos, fizemos o uso de uma linguagem acessível para que nos aproximássemos da realidade dos jovens. $E$, sobretudo, trabalhássemos assuntos que impactam os seus cotidianos como, por exemplo, o preconceito, a violência e o bullying. Foi por isso que resgatamos a filosofia levinasiana, pois uma das possíveis leituras da ética da alteridade é, a saber, sobre a dignidade da vida do outro e, ao fazer práticas como bullying, fere-se a dignidade. Agindo dessa maneira impede-se a abertura à exterioridade ou dito de outro modo: impede-se a manifestação do rosto do outro, pois "o rosto onde se apresenta o Outro - absolutamente outro" (LÉVINAS, 2000, p.181).

Tendo feito, na primeira mesa, essas considerações sobre a responsabilidade pela vida do outro, partimos para a segunda mesa com a seguinte provocação: qual é o máximo de não tratar a vida do outro com respeito? Ou melhor: o que acontece quando se esquece da humanidade do outro e trato-o como objeto? Para tanto, escrevemos um breve ensaio cujo título é: A Educação: Um Grão de Areia no Saara. Exploramos o limite da desumanização com o exemplo do nazismo na II Grande Guerra Mundial, discutimos, ainda que brevemente, o conceito de banalidade do mal ${ }^{1}$ da filósofa Hannah Arendt, cujo intuito era falarmos de atos vis que são perpetrados sem o mínimo de reflexão humana ou moral.

Além de tudo, levamos alguns trabalhos do fotógrafo Sebastião Salgado², pois as suas lentes conseguiram captar a desumanização que o ser humano foi submetido na nossa contemporaneidade, seja por vias de guerras civis, seja por trabalhos desumanos ou, até mesmo, a fome. Logo abaixo podemos ver duas fotografias que mostramos aos estudantes. Na primeira imagem vemos corpos empilhados por um trator do exército 
francês em Ruanda no ano de 1994 e na segunda vemos refugiados do povoado de Lula, Kongo Orientais, chegando ao povoado de Kisesa no Zaire em 1977. Vejamos:

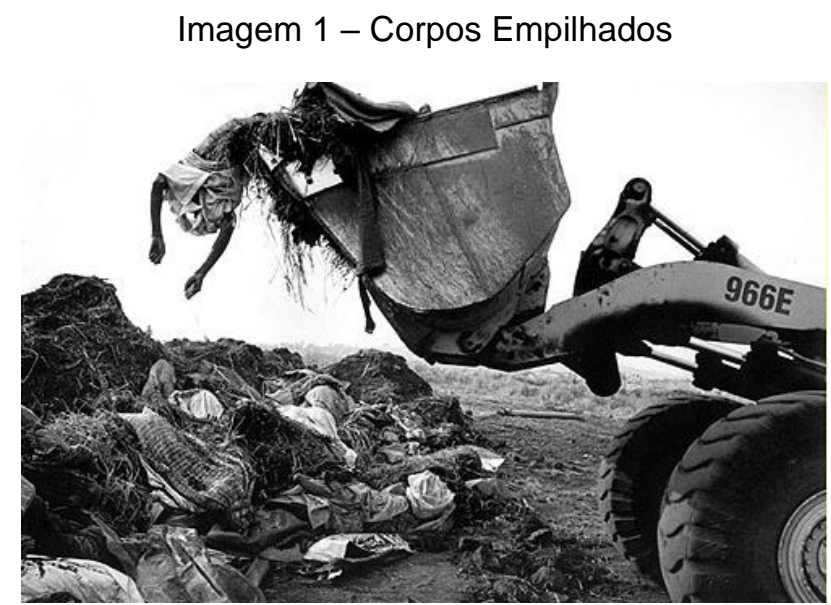

Fonte: documentário "O Sal da Terra" de Juliano Salgado \& Wim Wenders de 2014.

Imagem 2 - Refugiados

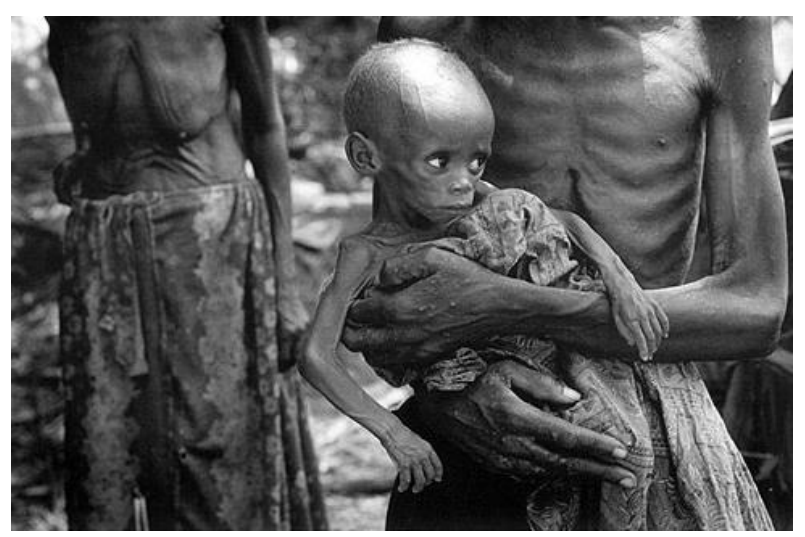

Fonte: Sebastião Salgado publicado no jornal “El País” em 2019.

Após a exposição do tema da desumanização e a guisa de concluirmos a nossa segunda e última palestra do simpósio, retomamos à discussão sobre a importância do cuidado de si e para com o outro e como a noção de responsabilidade pela vida do outro é fulcral na tentativa de mitigar os atos violentos no mundo. Todavia, naquele momento primordial, trouxemos a luz o movimento da poesia lírica grega arcaica para retratar o 
tema do amor, pois a lírica se preocupava com os sentimentos dos seres humanos no mundo e sobre a finitude da vida, sobre a única certeza que temos: a morte. E, então, instigamos os estudantes a pensarem o que eles farão nesse intervalo, entre a vida e morte. Ressaltamos que nesse intervalo é fundamental a noção de empatia adquirida através do amor, ponto central na formação humana. Nas palavras de Jacyntho Lins Brandão e Magda Guadalupe dos Santos, leiamos:

\begin{abstract}
A descoberta do amor faz, pois, parte orgânica da grande aventura grega que é a descoberta do homem. Ousaríamos mesmo afirmar que a descoberta do amor na Grécia constitui, efetivamente, a primeira forma de humanismo no seio de nossa cultura, antes que o predomínio do racional se estabelecesse, já no século $\mathrm{V}$, expulsando da esfera da investigação antropológica os problemas referentes ao predomínio do volitivo-sentimental (BRANDÃO \& SANTOS, 1980, p.118).
\end{abstract}

Por outro lado, faz-se necessário ressaltar que por mais robusto e complexo os assuntos que levamos para os estudantes no evento, para a preparação das escritas dos ensaios, da montagem dos materiais visuais apresentados nas palestras, foi feita a tradução de linguagem necessária para que tais questões se tornassem profícuas e notáveis pelos estudantes do ensino médio.

\title{
Oficinas
}

Continuando a nossa descrição sobre o simpósio, relataremos nesse tópico sobre o acontecimento das oficinas feito pelos estudantes do segundo ano do ensino médio. Eles foram responsáveis por comunicar trabalhos, feitos por eles próprios, sobre o seguinte tema: ser "ser humano". Foram oferecidas oito oficinas ao todo, distribuídas da seguinte forma: duas oficinas sobre a disciplina de filosofia, duas sobre sociologia, duas sobre história e, por fim, duas sobre geografia. A proposta central era que aquele fosse um momento de formação e interdisciplinaridade em relação ao tema geral do simpósio, trazendo um enfoque diferente dentro do olhar de cada disciplina. As oficinas tiveram média de quarenta e cinco minutos de apresentação e quinze minutos de perguntas e reflexões destinadas aos participantes. 
Em cada oficina foi trabalhado um tema específico: (1) filosofia: coordenado pelo professor Walter Vieira Junior, cujo tema era: "O conhecimento do conceito de pessoa na relação entre o sujeito e o outro ao longo da história"; (2) sociologia: sob a coordenação dos professores Márcio José Pereira e Elizandra Cristina Vaz Bertoldo, com a seguinte temática: "As relações sociais e as redes sociais"; (3) história: com a orientação do professor José Joaquim da Costa, cujo tema era: "O Ser humano artífice da sua própria história" e, por fim, (4) geografia: coordenados pelos professores Carlos Mariano da Silva e Claudine José de Freitas, com o tema: "O ser humano como colaborador do meio ambiente".

Nas oficinas de filosofia, os estudantes apresentaram trabalhos baseados em autores como Santo Agostinho, São Tomás de Aquino, Descartes, Hume e Freud. Cada estudante teve a liberdade de direcionar a sua apresentação, escolhendo métodos e abordagens diferentes, segundo orientação e correções dos professores. Ao trabalhar um mesmo tópico sob uma perspectiva interdisciplinar, os estudantes-ouvintes dos primeiros anos puderam escolher quais oficinas assistiriam.

Nas imagens abaixo, podemos ver fotos da escola no dia do simpósio. Na imagem 3 vemos a entrada da escola decorada pelos estudantes do terceiro ano e na imagem 4, vemos a palestra que aconteceu no período da tarde.

Imagem 3 - Entrada da Escola

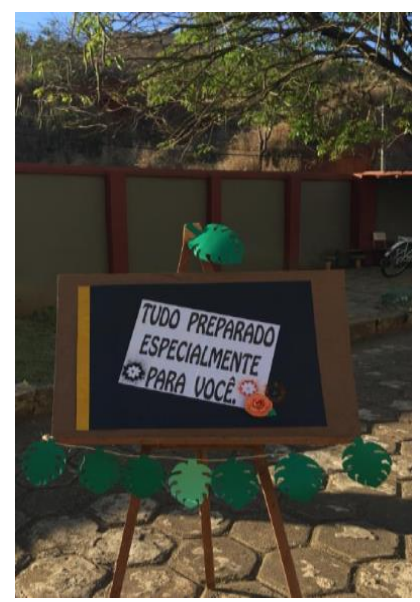


Fonte: das autoras

Imagem 4 - Palestra Principal da Tarde

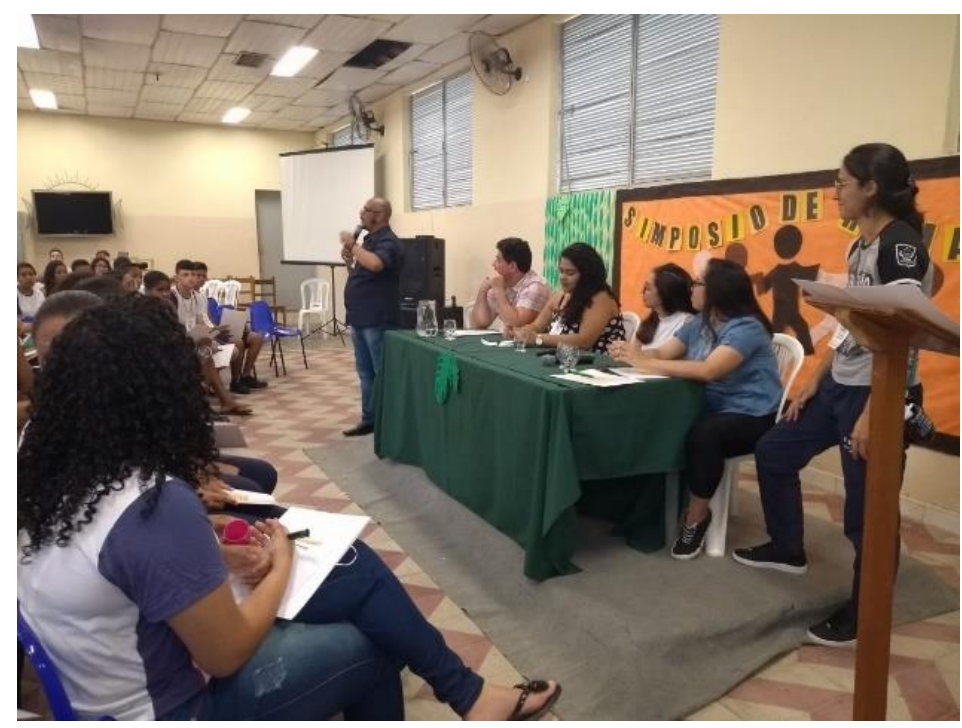

Fonte: das autoras

\section{Metodologia}

Muito se tem escrito e debatido sobre a importância do ensino da filosofia e da capacidade de pensar dentro e fora da sala de aula. Matthew Lipman, filósofo estadunidense, foi um importante pensador no que diz respeito à educação filosófica, sobretudo, para crianças. No entanto, depois da nossa experiência na Escola Estadual de Raul Soares percebemos que o pensamento de Lipman pode, também, ser aplicado ao ensino de jovens e adolescentes. Portanto, veremos a seguir como a execução de um simpósio com estudantes do ensino médio pode ser uma oportunidade de ensino/aprendizagem bastante pertinente.

Matthew Lipman acredita na capacidade das crianças desenvolverem seu próprio pensamento crítico, uma vez que o sistema educacional tem a capacidade de nutrir essa tendência natural ao pensamento e, por conseguinte, contribuir para um mundo no qual as pessoas são capazes de pensar por elas mesmas. Lipman trabalha com a hipótese de que a filosofia "quando propriamente reconstruída e propriamente trabalhada" (LIPMAN, 
1991, p.3), tem a grandiosa capacidade de trazer o mais alto nível do pensamento na educação do que qualquer outra forma de abordagem.

Além disso, o filósofo defende que uma abordagem efetiva do ensino inclui questões como: noções de comunidade, pesquisa, narrativa e diálogo. Lipman acredita que se esses pontos supracitados forem tratados com seriedade, isso permitirá aos estudantes a oportunidade de desenvolver um potencial cognitivo mais robusto quando comparado a uma abordagem sem levar em consideração tais questões (LIPMAN, 1991, p.3).

Além dos mais, Lipman também defende que a filosofia deveria ter uma versão acessível às crianças, pois "a filosofia começa quando podemos discutir a linguagem que usamos para discutir o mundo" (LIPMAN, 1995, p. 37). Sendo assim, argumenta que a sala de aula tradicional deve se transformar na participação ativa dos estudantes e professores, sempre em diálogo sobre os problemas em questão.

No entanto, é importante resgatarmos a diferença entre diálogo e uma "mera" conversação. Lipman aponta que uma "mera" conversação é uma forma inócua de discussão, isto é, geralmente exibe uma ausência de sensatez e fundamentação teórica e, como resultado, temos indivíduos superficiais ao fim de uma conversação não orientada pelo rigor e profundidade. De outra forma, o diálogo pode ser pensado como um questionamento deliberativo, pois contém o esforço da exploração cognitiva, juntamente com questionamentos específicos e complexos (LIPMAN, 1998, p. 277).

Por outro lado, a conversão de linguagem acadêmica para uma linguagem acessível não é uma necessidade única do ensino para crianças, mas, também, para o ensino com jovens e adolescentes. Decodificar jargões próprios da filosofia, fazer associações de pensamentos filosóficos com os desafios e dilemas cotidianos dos estudantes assim como com a cultura deles é essencial para manter um sistema de ensino/aprendizagem que faça sentido para suas vidas. Afinal, nas palavras de Bell Hooks: 
voz engajada não pode ser fixa e absoluta. Deve estar sempre mudando, sempre em diálogo com um mundo fora dela (HOOKS, 2020, p. 22).

Nesse sentido, as palestras pensadas, por nós autoras, para o simpósio foram preparadas tendo em vista uma linguagem acessível para os estudantes do ensino médio, o que, consequentemente, fez com que eles se sentissem mais confortáveis e questionadores na discussão. A ideia central era tornar o ambiente tradicional de escuta passiva do estudante em um espaço de diálogo e participação ativa, afinal, segundo Hooks: "Muitas vezes, antes de o processo começar, é preciso desconstruir um pouco a noção tradicional de que o professor é o único responsável pela dinâmica da sala" (HOOKS, 2020, p.18). Para isso, na primeira palestra, como mencionado no tópico anterior, levamos perguntas direcionadas aos estudantes para instigar a interação. Posteriormente, indagando sobre "quem realmente somos", conduzimos a discussão para as consequências da ansiedade social causadas pelas redes sociais e pelas inúmeras tarefas do dia a dia. Desta maneira, ainda em consonância com Hooks, "a visão constante da sala de aula como um espaço comunitário aumenta a probabilidade de haver um esforço coletivo para criar e manter uma comunidade de aprendizado" (HOOKS, 2020, p. 18).

Assim, outro ponto valoroso nesse simpósio é que os estudantes aprenderam consigo mesmos, afinal, foi atribuído a eles um protagonismo até então desconhecido pelos próprios. Ora, os estudantes do segundo ano tiveram a liberdade de escolher abordagens e materiais para ministrar as oficinas, enquanto os estudantes do primeiro ano eram ouvintes dessas explanações, trazendo assim, a noção de proximidade e proporcionando a quebra da relação entre professor e estudante. Lipman, Sharp \& Oscanyan afirmaram, justamente, a importância de os estudantes aprenderem uns com os outros e consigo mesmos (LIPMAN, SHARP \& OSCANYAN, 1994, pp. 117-137). Além disso, Sleeper ressalta que essa liberdade de ensino deve ser cada vez mais incentivada, leiamos:

Deveríamos preparar os nossos estudantes a ensinar os seus próprios assuntos, seus próprios currículos, filosoficamente... estaríamos ensinando a eles que a filosofia é uma disciplina de exame crítico e inquisitivo. Nós 
estaríamos ensinando a eles que a filosofia pode ser aplicada em todas as disciplinas do currículo escolar (SLEEPER,1978, p.237).

Em consequência de tal protagonismo, podemos trazer a luz o exemplo de um ocorrido em uma das oficinas de filosofia: a estudante responsável pela apresentação da oficina indagava sobre o que é uma família. Dessa forma, os exemplos ilustrados giravam em torno de uma família composta por um homem e uma mulher, que se casavam e tinham filhos. À vista dessa exposição, um estudante do primeiro ano, ouvinte, levantou questionamentos sobre gênero e sexualidade, questionando sobre as demais constituições familiares, isto é, a pluralidade de possibilidades que pode formar uma família. Percebemos aqui que, através do ambiente propício à fala, o estudante tomou o lugar de argumentador ativo, usando o pensamento crítico para levantar suas questões. Ainda assim, compreendemos que, conforme Hooks:

\begin{abstract}
A falta de disposição de abordar o ensino a partir de um ponto de vista que inclua uma consciência da raça, do sexo e da classe social tem suas raízes, muitas vezes, no medo de que a sala de aula se torne incontrolável, que as emoções e paixões não sejam mais represadas. Em certa medida, todos nós sabemos que, quando tratamos em sala de aula de temas acerca dos quais os alunos têm sentimentos apaixonados, sempre existe a possibilidade de confrontação, expressão vigorosa das ideias e até o conflito. (HOOKS, 2020, p. 55).
\end{abstract}

Sendo assim, constatamos a importância de ouvir o que os estudantes têm a dizer, assim como também, a urgência na formação de docentes para lidar com tais assuntos com os discentes. Dessa forma, recorremos a uma passagem de Souza em consonância à nossa experiência, leiamos:

O ensino da filosofia consiste em reconhecer e seguir bem de perto aquilo que as crianças estão pensando, ajudando-as a verbalizar e objetivar esses pensamentos e, depois, cuidando do desenvolvimento das ferramentas que necessitam para refletir a respeito desses pensamentos (SOUZA, 2013, p. 17).

Em suma, compreendemos que a inserção do ensino da filosofia nas escolas através da experiência com um simpósio é olhar para os nossos jovens, não como adultos em miniaturas, mas como pessoas que quando ensinadas e incentivadas a pensar por 
conta própria, tornar-se-ão indivíduos sensatos em suas relações. Afinal, "ouvir um ao outro (o som de vozes diferentes), escutar um ao outro, é um exercício de reconhecimento. Também garante que nenhum aluno permaneça invisível na sala" (HOOKS, 2020, p.58).

\section{Considerações Finais}

O ensino de filosofia é um desafio a ser enfrentado e não se trata de um problema atual. Com esta experiência de participar de um simpósio em uma escola estadual, tivemos a oportunidade de colocar em prática uma metodologia de ensino filosófico não tradicional que pôde ajudar no desenvolvimento de habilidades do pensar e habilidades filosóficas práticas. Dessa forma, pudemos romper, mesmo que por um dia, a habitual estrutura tradicional da sala de aula, trazendo a oportunidade dos estudantes se desenvolverem com outra abordagem: o protagonismo estudantil.

Tirar os estudantes da Escola Estadual Regina Pacis de suas atividades rotineiras e posicioná-los à frente de um simpósio, seja no âmbito operacional, seja no âmbito das comunicações, transferiu para eles responsabilidades tanto para com o outro quanto para com a educação. Torná-los protagonistas em suas pesquisas e em suas comunicações provocou a oportunidade de vivenciar a autonomia e a emancipação em suas vidas. Abaixo podemos ler relatos de dois estudantes sobre a experiência do simpósio:

1. "Eu fiquei impressionada pelo fato de uma escola que seja dividida entre os alunos tenha se unido e deixado de lado todas as diferenças por um único propósito: realizar o sonho do melhor professor de filosofia. Além disso, também aprendemos a ter paciência para com o outro e reforçamos a noção de ajudar quem precisa." - Estudante 1.

2. "O olhar e a atenção dos alunos com as graduandas foram excelentes. Elas retiraram dúvidas e abriram olhares em relação ao ensino." - Estudante 2.

\section{Referências}

BRANDÃO, Jacyntho Lins \& SANTOS, Magda Guadalupe dos. Morte e Amor: a Construção do Humano na Lírica Grega Arcaica. Ensaios de Literatura e Filologia. v.4, pp. 117-161. 1983. 
HADOT, Pierre. Exercícios Espirituais e Filosofia Antiga. São Paulo: É Realizações, 2014.

HOOKS, Bell. Ensinando a Transgredir: A Educação como Prática de Liberdade. São Paulo: Martins Fontes, 2020.

LASSALLE, Xavier. O Genocídio de Ruanda, Pelo Olhar de um Mestre da Fotografia. EI País. Disponível em: https://brasil.elpais.com/brasil/2019/04/05/album/1554460759_554970.html\#foto_gal_3>. Acesso em: 12 maio. 2021.

LÉVINAS, Emmanuel. Totalidade e Infinito. Lisboa: Edições 70, 2000.

LIPMAN, Matthew. O Pensar na Educação. Rio de Janeiro: Vozes, 1995.

LIPMAN, Matthew. Thinking in Education. New York: Cambridge, 1991.

LIPMAN, Matthew. Teaching Students to Think Reasonably: Some Findings of the Philosophy for Children Program. The Clearing House. v. 71, n. 5, pp. 277-280. 1998.

LIPMAN, Matthew; SHARP, Ann Margaret. \& OSCANYAN, Frederick. A Filosofia na Sala de Aula. São Paulo: Nova Alexandria, 1994.

ROSA, Luís Carlos Dalla. Educar Para a Sabedoria do Amor: A Epifania do Rosto do Outro Como uma Pedagogia do Éxodo. São Leopoldo, 2010. 344f. Tese (Doutorado em Teologia) - Escola Superior de Teologia Programa de Pós-Graduação.

SALGADO, Juliano \& WENDERS, Wim. O Sal da Terra. 2014. (110 min.).

SLEEPER, Ralph. Pre-College Philosophy. The Social Studies. v. 69, n.6. 1978.

SOUZA, Tania Silva de. O Ensino de Filosofia para Crianças na Perspectiva de Matthew Lipman. Revista Filogênes. v. 6, n. 2, pp.13-26. 2013. 


\section{Notas}

1 Principal eixo argumentativo que atravessa as reflexões filosóficas de Hannah Arendt. Trata-se do paroxismo das experiências violentas perpetradas por governos totalitários. No entanto, a novidade em sua reflexão diz respeito ao ponto de vista da destruição sem qualquer motivação maligna, isto é, uma abordagem ético-política da naturalização da sociedade frente ao mal.

${ }^{2}$ Fotógrafo documental que, durante um período de sua vida, se dedicou a fotografar os horrores cometidos pela espécie humana.

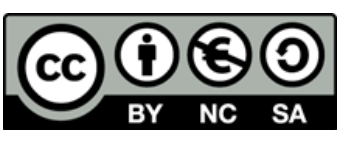

This work is licensed under a Creative Commons Attribution-NonCommercial 4.0 International (CC BY-NC 4.0) 